\title{
Evaluating the efficiency of the fluidity retention of ready-mix concrete during the transportation of it to the construction site
}

\author{
Oleksii Kabus ${ }^{*}$, Larisa Butska, Olga Makarenko, Lidiya Pershina, \\ and Andriy Tymoshchenko
}

Kharkiv National University of Civil Engineering and Architecture, Sumska st. 40, 61002 Kharkiv, Ukraine

\begin{abstract}
The work is devoted to the study of changes in the time of mobility of concrete mixtures, which are used for commercial concrete with monolithic construction. The in-situ concrete quality depends on the uniformity, viability and workability of the concrete mix intended for the transportation, unloading and workability at the construction site. One of the techniques used for the solution of this problem can be step-by-step addition of chemical admixtures or introduction of setting retarders whose efficiency is expressed in an increased resiliency of the concrete mix that is extended by two and more hours. Each solution has its advantages and drawbacks; therefore the efficiency can only be estimated under specific conditions taking into account the cost of concrete mix and opportunities for the realization of each individual solution. Were received results showing the presence of a problem of mobility loss of concrete mixtures with chemical additives of high water-reducing action. The use of such technological techniques as increasing the initial mobility and gradual introduction of supplements to superplasticizer proved to be effective technological solutions.
\end{abstract}

\section{Introduction}

The in-situ reinforced concrete finds wide application. It is produced using ready-mix concrete that is prepared at special-purpose works and transported to the construction site using truck mixers. State-of-art constructions of any size, shape and purpose are erected using this concrete.

The concrete placing process used for cast-in-place reinforced concrete constructions at the construction site requires the delivery of the mix from the works using the concrete haulers and the structure quality depends on the fluidity retention, uniformity and workability of the mixture intended for the transportation, unloading and laying. However, the hands-on experience shows that there is a danger of the loss of fluidity of concrete mixes especially in the conditions of long-distance transportation and at high ambient temperatures. In large cities with the distance between the concrete plants of 10 to $15 \mathrm{~km}$ it

Corresponding author: calorimetry_centr@ukr.net 
usually takes 30 to 40 minutes to transport and place the concrete mix. However, even under such conditions the Customer obtains very often the concrete mix of a low fluidity that requires the water addition.

Many research papers state the availability of the problem related to the loss of fluidity by concrete mixes containing concrete superplasticizer admixtures that happens with the elapse of time [1-4]. This phenomenon can be related to many factors: incompatibility of the admixtures with the cements and with each other, a low concentration of superplasticizers in the concrete mix, high ambient temperature, use of fine quickhardening cements, availability of flour and clay particles in the aggregates, etc. $[1,4]$.

If we approach the above problems from the standpoint of directional modifying of the properties of concrete mixes, we will see that different methods are available for their solutions. Cement setting retarders whose efficiency provides a two-hour increase and even more in the resilience retention of concrete mix have been known for ages. [3].

Providing specified parameters of process mixes in the conditions of long-distance transportation without the retardation of hardening processes is a very complicated engineering task indeed for the cast-in-situ construction. One of the technological methods of the solution of such a problem can be a stepwise addition of the admixtures [3].

In the event of stepwise addition one portion of the admixture (40 to $60 \%)$ is injected when the concrete mixes are prepared at concrete mortar plant and the other portion is added at the concrete mix placement site right in the structure (usually the admixture solution is poured into the rotary drum of concrete mixer truck). This method enables the renewal of the fluidity of concrete mix adding no water.

The admixture of a different type (plasticizers, superplasticizers, retarders, and accelerators) are combined together and can be introduced individually at different stages depending on the season of the year, arrangement scheme of concrete jobs, the distance to the construction site, taking into consideration the transportation cost and other factors [4].

The analysis done shows that the range of available technological methods of improvement of the properties of concrete mix can be extended from the "maintenance of the fluidity retention of concrete mixes" to "providing the required fluidity at the construction site". However, the most efficient and economic method should be selected in each specific case by way of experiment.

The objective of this research was to study and evaluate the efficiency of different formulation technology-related decisions that the producer of the ready-mix concrete can use to provide specified indices for the concrete mix to insure easy placing at the construction site.

\section{Materials and methods of research}

The following materials were used to do research:

- cement: Portland cement with the CEM II/ A-S-32.5 (PJSC "Podilsky Cement" CRH Ukraine);

- coarse aggregates: crushed granite Fr.5-10 (OJSC Malokokhnivskyi Granite Pit", Poltava region, city of Kremenchuk);

- $\quad$ fine aggregates: quartz sand with $\mathrm{Mk}=1.1$.(the Bezliudivskyi pit, Kharkiv region)

- chemical admixtures: superplasticizer (SP)-Sika Visco Greate 1020 UA, hardening retarder (C)-Sika Retarder and hydrophobization agent (G) - GKJ -11K (CPC Kremniypolymer")

At the first stage of experimental investigation carried out using mini-cone test we observed the compatibility of added superplasticizer and cement [6]. A plasticizing effect of the action of admixture depending on its concentration and availability of the tendencies to the erroneous hardening or a fast loss of the fluidity by the cement paste were assessed. The 
test procedure was as follows: the cement paste was prepared with SP admixture concentrations of $0.6 ; 0.8$ and $1.2 \%$ of the cement mass and the water-to-cement ratio of 0.4 . Then, the paste was placed into the mini-cone and its spread was measured after 5,30 , 60 and 90 minutes. Thereafter, the conclusion was made on the compatibility of SP with the selected cement.

The second stage of experimental investigation included the fabrication of the four series of specimens with different formulation technology decisions aimed at the production of a specified grade of the concrete mix with the fluidity of S4 after 1.5 hours following its preparation. The S4 grade $(16-20 \mathrm{~cm})$ was selected, because it is highly desirable for the production of ready-mix concrete and it is usually assumed to be basic for the tests [3, 7]. An opportunity for providing the wanted fluidity grade after 1.5 hours was investigated varying the formulation technology factors:

increasing the SP concentration;

increasing an initial fluidity of the concrete mix (a lower water reduction effect produced by the SP action);

introducing the admixtures retarding the cement hardening;

additional introduction of $25 \% \mathrm{SP}$ (of the initial value) after 1.5 hours;

stepwise addition of the SP admixture $(50+50 \%)$.

Table 1 gives the composition of concrete mixes. When the SP admixture was introduced the ratio of cement, crushed stone and sand remained unchanged. The consumption of components was calculated taking into consideration a real density of the concrete mix. The admixtures that retard the hardening were introduced to increase a resiliency of the concrete mix in time. The series of specimens had the following difference in principal:

series 1 -the reference composition had no admixtures;

series 2- the influence of the concentration of SP admixture and an increase in the initial fluidity for the achievement of required fluidity in specified time was investigated;

series 3 - simultaneous introduction with the SP admixture of the admixture that retard the cement hydration;

series 4- stepwise addition and additional introduction of the admixture after 1.5 hours following the preparation;

Concrete mixes were prepared in the laboratory concrete mixer of a forced action and tested according to the standard ISO 4109:1980 [9], in particular we measured the concrete mix fluidity, its retention in time during 1.5 to 2 hours and its density. To define the compression strength of concrete, the concrete specimens of 10x10x10 cm were prepared according to the standard EN 12390-1:2000 [10] and it was measured at an age of 2, 7 and 28 days.

\section{The results of research}

Table 1 gives the measurement data of the spread of cement pastes with a different concentration of SP using the mini-cone. Introduction of the SP admixture in the amount of $0.6 \%$ results in an increased spread of cement pastes ranging from $6.3 \mathrm{~mm}$ to $16.5 \mathrm{~mm}$; the increase in the concentration to $0.8 \%$ results in the increased spread reaching $20 \mathrm{~mm}$, that is not changed later on and it is indicative of the fact that the admixture saturation point has been reached.

The spread of cement pastes with SP after 5, 30, 60 and 90 minutes is not decreased; it is even increased (from $16.5 \mathrm{~mm}$ to $19 \mathrm{~mm}$ for the composition 2), which is indicative of the rheological compatibility of the admixture and the cement and unavailability of the problems with a long-term maintenance of an appropriate fluidity of concrete mixes. 
The research done allows us to assume that it is quite possible to produce concrete mixes with the fluidity stable in time.

Table 1. Cement paste test data.

\begin{tabular}{|c|c|c|c|c|c|}
\hline \multirow{2}{*}{ Item No } & Composition & \multicolumn{4}{|c|}{ Spread diameter, cm, minute } \\
\cline { 3 - 6 } & & 5 & 30 & 60 & 90 \\
\hline 1 & Reference & 6.3 & 5.3 & 5.8 & 5.8 \\
\hline 2 & $0.6 \%$ of SP & 16.5 & 17.8 & 19 & 19 \\
\hline 3 & $0.8 \%$ of SP & 20 & 20 & 21 & 20 \\
\hline 4 & $1 \%$ of SP & 20 & 20 & 20.5 & 20 \\
\hline
\end{tabular}

The test data of concrete mixes and concretes of the four series of specimens are given in Table 2. A decrease in the concrete mix fluidity for the reference series containing no admixtures was equal to $5 \mathrm{~cm}$ after 1.5 hours. The concrete mix grade remained at the level of S4 during 60 minutes, which is indicative of its rather high preservation in time. As for the plasticized concrete mixes (series 2) the fluidity change pattern differed significantly; the decrease in the fluidity ranged from 7 to $14 \mathrm{~cm}$ after 1.5 hours. For the series I, a decrease in the fluidity had a linear character ( 1 to $2 \mathrm{~cm}$ after 30 minutes) and for the series 2 it had an avalanche -like character, i.e. the slump was decreased by 4 to $11 \mathrm{~cm}$ after 30 to 60 minutes. An increase in the admixture concentration failed to result in the mix stabilization in time, though it resulted in an increased water reduction effect and an increased concrete strength. The $0.8 \%$ concentration of SP resulted in the increased strength of $19 \%$, and at $1.2 \%$ of SP this value was equal to $61 \%$ and at $1.6 \%$ of SP it was equal to $87 \%$. We can see a difference in the stability of cement pastes and concrete mixes in time and it can be related to the availability of additional disperse particles in concrete mixes that efficiently adsorb the SP admmixture.

Table 2. Test data of concrete mixes and concretes.

\begin{tabular}{|c|c|c|c|c|c|c|c|c|c|c|c|c|}
\hline \multirow{2}{*}{\begin{tabular}{c|c} 
Series \\
No
\end{tabular}} & \multicolumn{5}{|c|}{$\begin{array}{l}\text { Consumption of components per } 1 \mathrm{~m}^{3} \text { of the } \\
\text { concrete mix }\end{array}$} & \multicolumn{4}{|c|}{ Slump, cm. minutes } & \multicolumn{3}{|c|}{$\begin{array}{c}\text { Concrete } \\
\text { compression } \\
\text { strength, kgf } / \mathrm{cm}^{2} \text {, } \\
\text { days }\end{array}$} \\
\hline & $\mathrm{C}, \mathrm{kg}$ & $\begin{array}{l}\mathrm{CA}, \\
\mathrm{kg}\end{array}$ & $\begin{array}{l}\text { FA, } \\
\mathrm{kg}\end{array}$ & $\begin{array}{l}\mathrm{W} \\
\mathrm{kg}\end{array}$ & \begin{tabular}{|c|} 
Type of the \\
admixture and \\
its \\
concentration
\end{tabular} & 5 & 30 & 60 & 90 & 2 & 7 & 28 \\
\hline 1 & 375 & 1078 & 656 & 246 & - & 20 & 18 & 17 & 15 & 70 & 136 & 223 \\
\hline 2.1 & 379 & 1090 & 664 & 234 & $0.8 \% \mathrm{SP}$ & 20 & 18 & 15 & 10 & 82 & 168 & 266 \\
\hline 2.2 & 376 & 1081 & 658 & 242 & $0.8 \% \mathrm{SP}$ & 25 & 24 & 22 & 18 & 75 & 149 & 233 \\
\hline 2.3 & 390 & 1113 & 678 & 211 & $1.2 \% \mathrm{SP}$ & 20 & 13 & 9 & 9 & 99 & 194 & 360 \\
\hline 2.4 & 383 & 1101 & 670 & 225 & $1.2 \% \mathrm{SP}$ & 27 & 22 & 18 & 14 & 90 & 181 & 331 \\
\hline 2.5 & 397 & 1142 & 695 & 194 & $1.6 \% \mathrm{SP}$ & 20 & 20 & 16 & 8 & 134 & 260 & 416 \\
\hline 2.6 & 389 & 1119 & 681 & 205 & $1.6 \% \mathrm{SP}$ & 26 & 25 & 23 & 12 & 116 & 226 & 386 \\
\hline 3.1 & 387 & 1114 & 678 & 219 & $\begin{array}{l}1.2 \% \mathrm{SP} \\
+0.5 \% \mathrm{C}\end{array}$ & 20 & 13 & 8 & 8 & 113 & 230 & 366 \\
\hline 3.2 & 384 & 1105 & 673 & 208 & $\begin{array}{l}1.2 \% \mathrm{SP} \\
+0.2 \% \mathrm{G}\end{array}$ & 20 & 14 & 11 & 10 & 112 & 235 & 362 \\
\hline 4.1 & 390 & 1121 & 682 & 211 & $1.2 \%+0.3 \% \mathrm{SP}$ & 20 & 12 & 9 & $20 / 11 *$ & 129 & 242 & 380 \\
\hline 4.2 & 386 & 1110 & 676 & 208 & $0.6 \%+0.6 \% \mathrm{SP}$ & 9 & 4 & 4 & $20 / 10 *$ & 120 & 217 & 355 \\
\hline
\end{tabular}

* after 30 minutes following the admixture introduction 
With the increase in mobility to the value of S5 the water reduction effect was reduced, therefore the increase in the strength made up 5, 48 and 73\% accordingly (Fig.1). Due to an increase in the initial fluidity for one grade we managed to maintain the fluidity at the level of S4 during 60 minutes and it is a sufficient condition for the most cases of the construction in urban conditions. If we recalculate a required amount of the admixture to be introduced into the mixture with the mobility of S5 in order to reach an equivalent increment in the strength we will see that the increase in the admixture consumption makes up 0.15 to $0.25 \%$.To increased the concrete strength by $19 \%$ we need to introduce $0.95 \%$ of SP instead of $0.8 \%$, to increased the concrete strength by $61 \%$ we need to introduce 1.4 $\%$ of SP instead of $1.2 \%$, and in the case of $87 \%$ we need to introduce $1.85 \%$ of SP instead of $1.6 \%$.

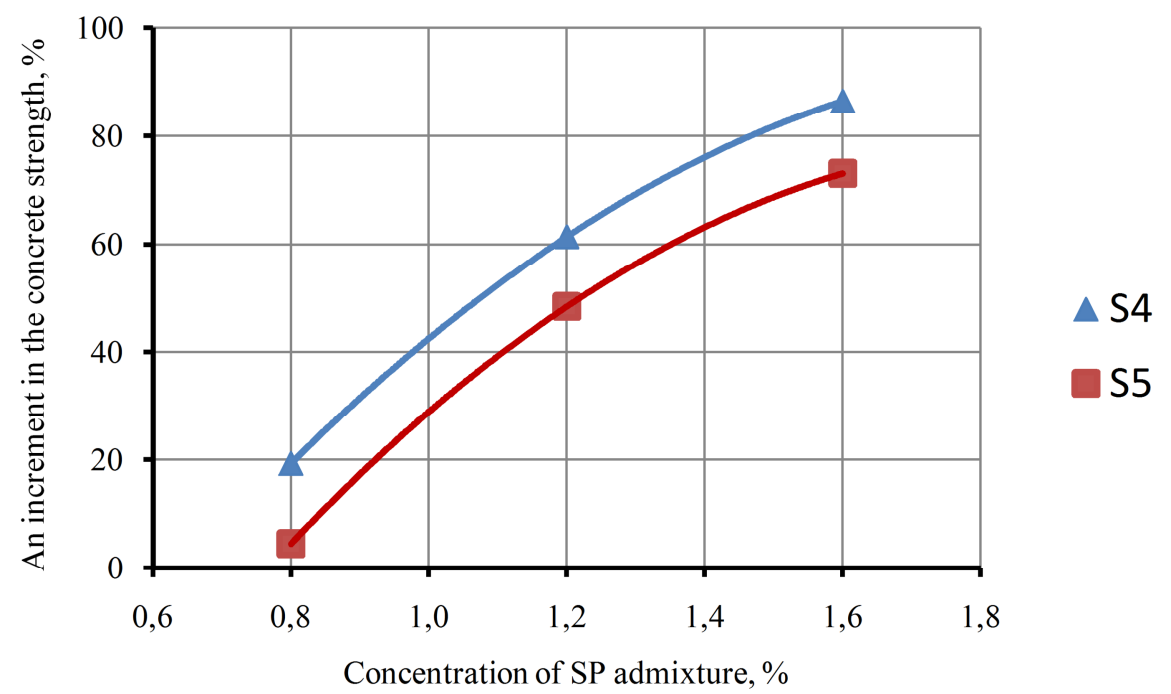

Fig. 1. Relationship of an increase in the concrete strength as a function of the concentration of SP admixture and the initial fluidity.

Addition of the retarding admixtures of cement hydration to the concrete mix (series 3) gave no desired outcome. Neither the hardening retarder $(\mathrm{C})$ nor the hydrophobization agent $(G)$ provided a stable fluidity for the concrete mix. A change in the increment of the strength of specimens for the series 3 is given in Fig.2. It is in the same range as for the specimens of the series 2 with the same amount of SP (series 2.3). 


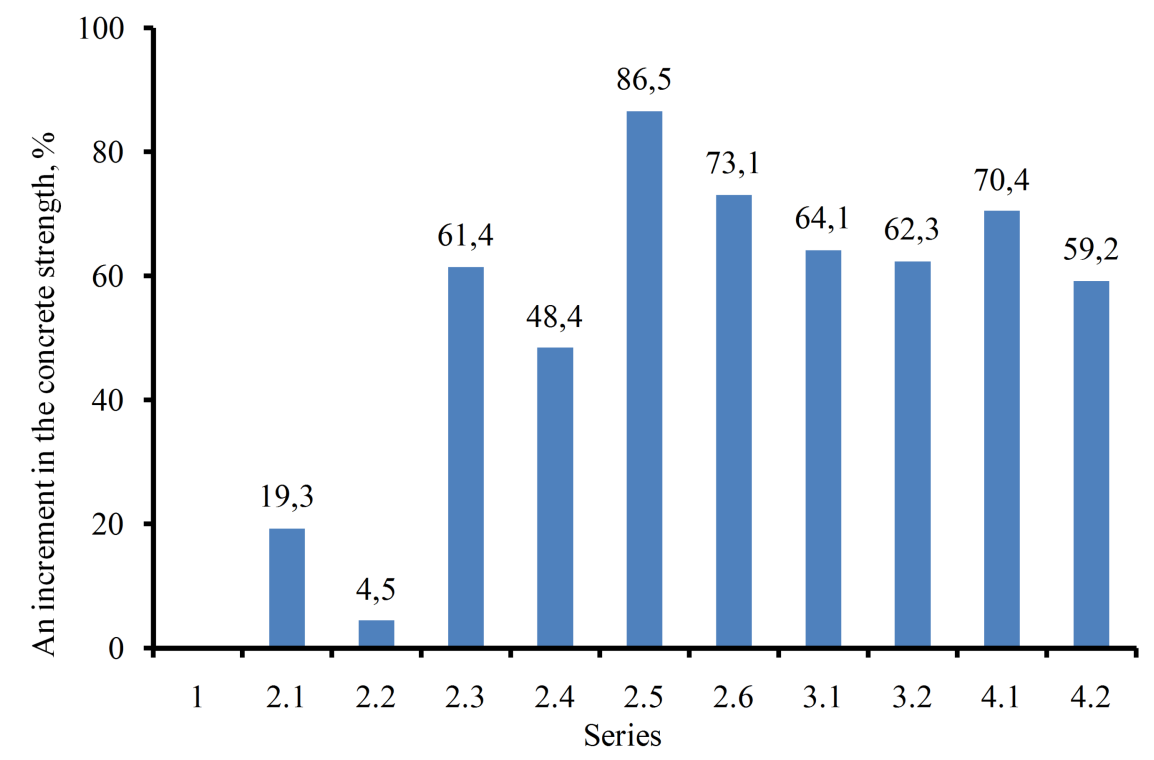

Fig. 2. An increment in the concrete strength for the test series of the specimens.

The last series of the tests (series 4) was related to the verification of the opportunity for the renewal of the fluidity of concrete mix after 1.5 hours following the preparation of it (series 4.1) and the efficiency of the stepwise addition of the admixture (series 4.2). An additional introduction of SP in the amount of $0.3 \%$ allowed us to restore completely the initial fluidity of the mix (Fig.3). The renewal of the mix fluidity through the additional introduction of SP indirectly confirms the unavailability of a sufficient amount of the free superplasticizer in the liquid phase that is necessary to reach a high fluidity of concrete mixes [8].

\section{Discussion of results}

An opportunity for the renewal of the cement fluidity due to the addition of SP is the most appropriate solution for the construction site. Such a necessity can be related to the unforeseen idle time (traffic congestion, equipment failure, etc.); therefore the available stock of the superplasticizer at the construction site can resolve the problem of the need of adding water in extreme cases.

Another method (stepwise addition) that requires the introduction of SP at the construction site is also rather efficient in this case and it requires no additional consumption of SP. However, the use of it can face the problems related to the transportation and technical opportunity for the mixing of the concrete mix of a low mobility (S1) in the concrete truck.

An increment in the strength in both cases was at the level of an ordinary introduction of the admixture and it was $9 \%$ higher at additional introduction of the admixture (Fig.2, series 4. 1). 


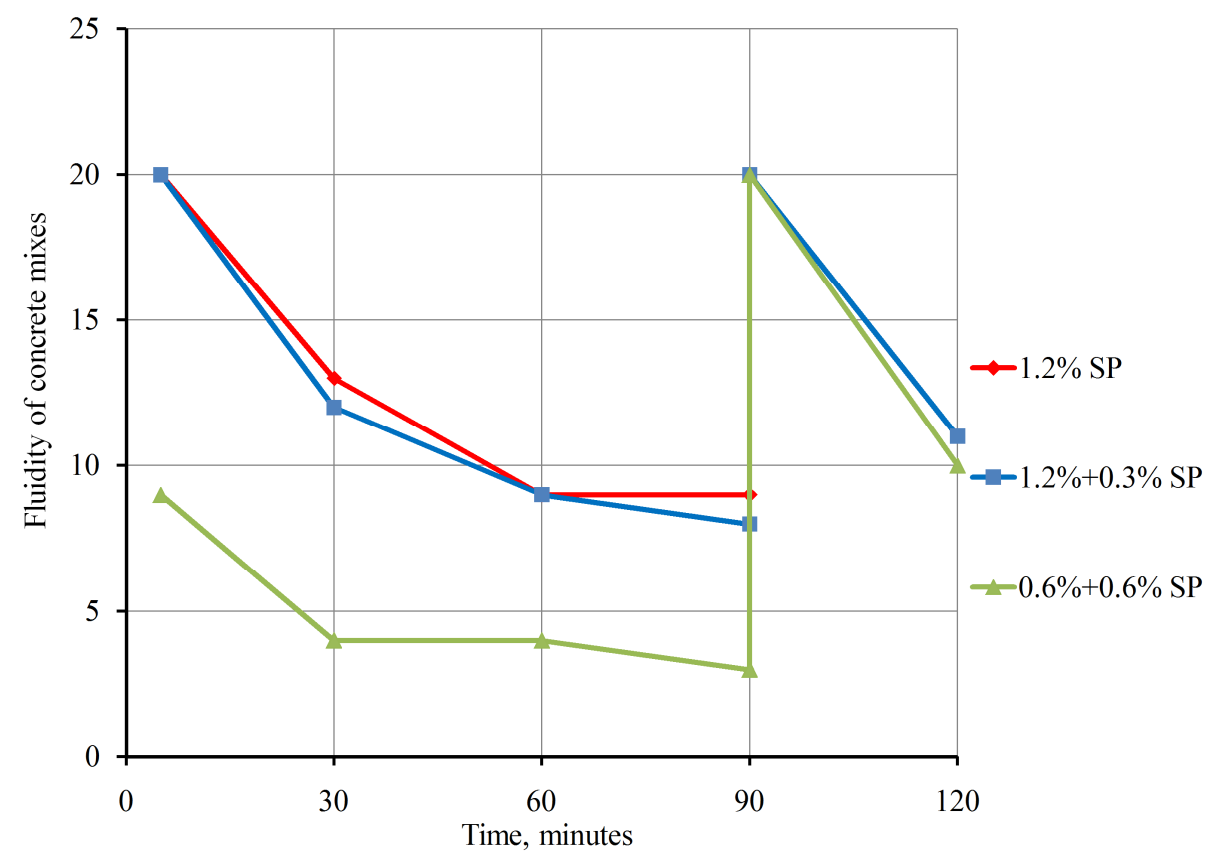

Fig. 3. A change in the fluidity of concrete mixes depending on the method of introduction of the SP admixture.

A drawback of these methods is the need for the time required for the mixing of concrete mix at the construction site and a short-time effect from the repeated admixture introduction. It must not be ruled out that in the case of need an additional amount of the admixture can be introduced several times.

A generalization of the most popular methods used for the maintenance of fluidity of concrete mixes in this research enabled the comparison of them with each other and attention was paid to the need of control of the workability of concrete mixes both at the plant and at the construction site to avoid undesirable phenomena of the degrading properties of concrete mixes and concretes.

\section{Conclusions}

Three technological techniques turned out to be effective, in particular a two-stage introduction of the admixture though it requires to spend additional time at the construction site and has a short-time effect; an increase in the initial fluidity of mix though it requires an increased admixture consumption in the range of 0.15 to $0.25 \%$; renewal of the mix fluidity due to the additional introduction of $0.3 \%$ of the admixture after 1.5 hours following its preparation that includes the drawbacks of two previous techniques, though it can provide the fluidity at a later time. Each solution has its own advantages and drawbacks, therefore their efficiency can only be evaluated under specific conditions taking into consideration the cost of concrete mix and the opportunities for the realization of each solution.

\section{References}

1 J. Punkki, ACI Materials Journal, 93 (1996). 
2 S.N. Tolmachev, E.A. Belichenko, A.V. Brazhnik. Construction Materials, 5 (2016)

3 A.N. Shakhov. Preservation of Cement Mixes: Contemporary Solutions of Everyday Issues. Concrete Technologies 3-4 (2012)

4 A.V. Usherov-Marshak, V.P. Sopov, Colloid Journal, 56 (4), 600-603 (1994)

5 V. Sopov, L. Pershina, L. Butskaya, E. Latorets, O.Makarenko, MATEC Web of Conferences, 116 (2017)

6 Taylor and other. Identifying Incompatible Combinations of Concrete Materials: Volume I-Final Report. U.S. department of transport. Federal highway admin (2006)

7 K. Hattori, Journal of the Society of Materials Science, 29, 318 (1980)

8 A.I. Vovk, Concrete Technology, 5 (2009)

9 ISO 4109:1980 Fresh concrete - Determination of the consistency - Slump test. International Standart. (1980)

10 EN 12390-1:2000 Testing hardened concrete - Part 1 Shape, dimensions and other requirements for specimens and moulds. (2000) 